\section{THE EFFECT OF BELOW EXPOSURE NOISE THRESHOLD LIMIT VALUE TO ACUTE STRESS}

${ }^{1} \mathrm{M}$ Mansyur, ${ }^{1} \mathrm{~A}$ Sulistomo, ${ }^{2} \mathrm{MB}$ Nurcahyo, ${ }^{2} \mathrm{E}$ Muslim, ${ }^{3} \mathrm{RI}$ Ismail. ${ }^{1}$ Universitas Indonesia, Community Medici, Jakarta, Indonesia; ' ${ }^{2}$ niversitas Indonesia, Industrial Engineer, Jakarta, Indonesia; ${ }^{3}$ Universitas Indonesia, Psychiatry Department, Jakarta, Indonesia

\subsection{6/oemed-2018-ICOHabstracts. 1456}

Introduction This study aims to examine the possibility of the effect of noise with intensity below the threshold value to stress.

Method The study is a quasi-experimental involved 108 subjects divided into 6 noise exposure groups of control, $0 \mathrm{dBA}$, $70 \mathrm{dBA}, 75 \mathrm{dBA}, 80 \mathrm{dBA}$ and $85 \mathrm{dBA}$ in $15 \mathrm{~min}$ exposure. Research subjects consisted of healthy males, aged 18-39 years and met the study criteria. Assessment of stress include physical stress index (PSI), the total power (TP) and low frequency/high frequency ratio (the ratio of $\mathrm{LF} / \mathrm{HF}$ ) measured using the test heart rate variability (HRV), adrenaline and cortisol blood levels measured before and after treatment.

Result Research subjects who qualify as many as 102 people a year aged $23.99 \pm 4.77$ years. Research subjects have equal characteristics between treatment groups according to the socio-demography.

There is no different of PSI value, the ratio of TP and LF/ $\mathrm{HF}$, Adrenaline between exposure groups. Cortisol levels were positively correlated with higher levels of adrenaline $(r=0.35$, $\mathrm{p}<0.01)$ while adrenaline levels and cortisol levels were strongly positively correlated $(\mathrm{r}=0.53, \mathrm{p}<0.01)$. PSI values weakly positively correlated with cortisol levels $(\mathrm{r}=0.2$, $\mathrm{p}<0.05$ ) and the ratio $\mathrm{LF} / \mathrm{HF}$ were positively correlated weakly with cortisol $(\mathrm{r}=0.2, \mathrm{p}<0.05)$.

Discussion Effect of noise on the stress intensity visible starting at Laeq, $65 \mathrm{dBA}$ and Laeq 8 hour, 8 hour $70 \mathrm{dBA}$. Correlation parameter values autonomic balance system with adrenaline and cortisol levels demonstrate the potential use of HRV as a psychophysiological assessment instruments due to noise disturbance.

\section{RE-EMPLOYMENT NEEDS AND BARRIERS OF INDIVIDUALS IN A RESIDENTIAL REHABILITATION PROGRAM}

D Madigan*, TP Johnson, L Forst, LS Friedman. University of Illinois at Chicago, Chicago, USA

\subsection{6/oemed-2018-ICOHabstracts. 1457}

Introduction Adverse effects on individual well-being as a result of unemployment are well-documented. Individuals in transitional housing programs often have a goal of reaching stable employment, but the unique needs and barriers for achieving re-employment among this diverse population (includes individuals that may be homeless, formerly incarcerated, or impacted by other stressful life circumstances) warrants further study to enhance programmatic and service recommendations.

Methods A structured interview guide was developed and modelled after existing validated surveys. To evaluate the ability of the instrument to optimally measure the constructs of interest, cognitive interviewing was conducted to identify problems in comprehension, retrieval, judgement and response to survey questions so that the survey can be modified prior to full deployment. The survey was administered orally by one interviewer and audio recorded. Descriptive data analysis was done for this exploratory semi-qualitative study.

Result Fifteen cognitive interviews were completed resulting in changes in content, wording, study inclusion criteria, and development of response categories. Over thirty interviews were conducted using the final guide. Results suggest that work histories of participants are more extensive with longer periods of employment than may be expected. Many respondents indicated that future employment goals include owning their own business and may represent an area of additional needed training for those currently unemployed. However, most aspirations for future employment were congruent with past achievements, including ownership.

Discussion It is important to assess the needs and barriers of those seeking employment services to ensure programs deliver essential services. Ownership may help bypass some of the challenges faced with finding and maintaining employment due to criminal records or other barriers. This interview guide will be used in other populations seeking varied employment services from community organisations to further study needs and barriers for regaining employment.

\section{UNEMPLOYMENT FOR LEARNING-DISABLED ADULTS AND FAMILY CARERS - BARRIERS AND CHALLENGES TO WORK: FINDINGS FROM A UK PUBLIC CONSULTATION}

1,2,3Prosenjit Giri* ${ }^{3}$ jill Aylott. ${ }^{1}$ Sheffield Teaching Hospitals Nhs Trust, Worksop, UKi ${ }^{2}$ Sheffield University, UK; ${ }^{3}$ International Academy of Medical Leadership, Dronfield, Derbyshire, UK

\subsection{6/oemed-2018-ICOHabstracts. 1458}

Introduction Disabled people (approximately 1 billion among 7.4 billion world population) and their Family-Carers suffer from massive labour market disadvantage. Global economic crisis and austerity has had serious implication on their health and well-being by increasing mortality, morbidity, poverty and poor access to health/social care. Over $50 \%$ of 1.5 million Learning-Disabled people in the UK lived in family-house depending on informal unpaid care from 0.84 million FamilyCarers resulting in significant financial burden for their family (2011). Despite Government initiatives employment rate among Learning-Disabled adults has fallen (6.1\% in 2009/10\% to $5.8 \%$ in 2015/16). $33 \%$ of Family-Carers were also unemployed compounding their misery.

Methods A public consultation within a local authority set out to review the current employment status and perception towards work among Learning-Disabled adults and their Family -Carers. Qualitative and quantitative data was gathered and analysed thematically and statistically respectively.

Results Among 227 participating Learning-Disabled adults, $98 \%(217 / 227)$ were in the working-age group (18-65 years) but only $8 \%(18 / 227)$ in paid employment. Among responding Family-Carers (77\%; 59/77 in the working age), 55\% were unemployed. Both the Learning-disabled adults $(74 \% ; 167 /$ $227)$ and Family-Carers $(50 \% ; 35 / 70)$ were unenthusiastic about their employment prospect. Negative societal attitude; bullying, harassment and crime; lack of access, resources, transport, training facility and targeted job opportunity were identified as primary barrier for work by the Learning-Disabled group. Caring responsibilities, increasingly scarce resources and Lack of social and management support were identified by the Family-Carers. The respondents called for a 
paradigm shift from employment support towards teaching/ training for employers and employees to break these barriers.

Conclusion Despite government initiatives, employment for Learning-disabled adults and their able Family-Carers remains an unfulfilled dream. More targeted employment, teaching/ training and flexible-working acknowledging the fragile interdependent relationship between Learning-disabled adults and Family-Carers, may prevent a significant loss of manpower and productivity.

\section{VIBRATION INDUCED INJURIES IN HANDS IN LONG- TERM VIBRATION EXPOSED WORKERS}

L Gerhardsson*, M Hagberg. Dept of Occupational and Environmental Medicine, Gothenburg University, Gothenburg, Sweden

\subsection{6/oemed-2018-ICOHabstracts. 1459}

Introduction Long-term vibration exposure may cause neurophysiological disturbances such as dampness and tingling, reduced grip strength and difficulties in handling small objects. Most of the exposed workers are right-handed and thus, the right hand will usually have a higher vibration exposure than the left hand. In this study we are comparing neurophysiological test results in the right and left hand in long-term vibration exposed workers. The underlying hypothesis is that signs of adverse health effects would be more pronounced in the right hand of the workers.

Methods The study is based on 47 (36 males and 11 females; mean-age $50 \pm 12 \mathrm{y}$; mean exposure time $16 \mathrm{y}$ ), all former patients from the department of occupational and environmental medicine, Gothenburg university. The comparison group consisted of 29 randomly selected subjects from the general population of Gothenburg. All participants completed several questionnaires and had a standardised medical examination. Thereafter, neurophysiological tests such as muscle strength tests and the determination of thermal and vibration thresholds were performed.

Results No significant differences were found for temperature and vibration thresholds in dig 2 and 5 bilaterally among the workers. Finger muscle tests (Pinch-grip and 3 Chuck grip) were also of the same magnitude in the right and left hand. Hand grip strength (Jamar), however, was significantly higher in the right hand of the workers.

Conclusions Although differences as regards symptoms and neurophysiological test results in the right and left hand of exposed workers have been reported in several studies, the only significant difference noted in this study was a somewhat higher grip strength in the right hand of the workers. That is to be expected, as most of the participants were right handed and therefore probably stronger in their dominant hand.

\section{EVALUATION OF THE KURTOSIS METRIC IN THE PREDICTION OF HEARING TRAUMA IN HUMANS ASSOCIATED WITH INDUSTRIAL NOISE EXPOSURES}

${ }^{1}$ Wei Qiu*, ${ }^{2}$ Mei-bian Zhang, ${ }^{3}$ Chuck A Kardous, ${ }^{3}$ Thais C Morata, ${ }^{3}$ William J Murphy, ${ }^{1}$ Roger P Hamernik. 'State University of New York at Plattsburgh, Plattsburgh, USA; ${ }^{2}$ Zhejiang Provincial Centre for Disease Control and Prevention, Hangzhou, China; ${ }^{3}$ National Institute for Occupational Safety and Health, Cincinnati, USA
Introduction It is clear from numerous experiments that current noise standards underestimated hearing trauma by complex noise (defined as a background Gaussian noise with embedded high-level transients), and that an energy metric alone is not sufficient to characterise a complex noise for hearing conservation purposes. In this study, a statistical metric of the noise amplitude distribution known as the kurtosis, is evaluated in the prediction of hearing trauma in humans associated with industrial noise exposures.

Methods A human database including 1500 subjects exposed to diverse industrial noises $(\mathrm{n}=650$ Gaussian noises, $\mathrm{n}=850$ complex noises) was used to analyse the interaction between an energy metric and kurtosis with respect to noise-induced hearing loss (NIHL). Two kurtosis-corrected NIHL prediction models are studied. One kurtosis correction was made through the exposure time; the other was made through exposure energy. The prevalence of NIHL was determined based on:

- at least of the adjusted hearing threshold levels (HTLs), in either ear, at 3, 4, or $6 \mathrm{kHz}$ is equal to or greater than $30 \mathrm{~dB}$;

- an average of the HTLs for both ears that exceeds $25 \mathrm{~dB}$ at $1,2,3$, and $4 \mathrm{kHz}$.

Results The dose-response relation for the complex noiseexposed subjects showed a higher prevalence of hearing loss for a comparable cumulative noise exposure (CNE) than did the Gaussian noise-exposed subjects. By introducing the kurtosis variable into the CNE calculation, the two dose-response curves could be made to overlap, essentially yielding an equivalent noise-induced effect for the two study groups.

Conclusion Kurtosis adjustment of CNE improved the correlation with NIHL and provided a single metric for doseresponse effects across diverse types of noise. The kurtosisadjusted CNE metric may be a reasonable candidate for use in NIHL risk assessment across a wide variety of noise environments

\section{VOCAL EFFORT IN TEACHERS: DOSE MEASUREMENTS AND CLASSROOM ACOUSTIC PARAMETERS}

R Sisto*, D Annesi, P Nataletti, F Sanjust, A Moschetto, L Cerini. INAIL Research, Department of Occupational and Environmental Medicine, Epidemiology and Hygiene, Monteporzio Catone, Italy

\subsection{6/oemed-2018-ICOHabstracts.1461}

Introduction Literature data show that teachers are exposed to increased risk for diseases of the phonatory apparatus. This circumstance is explained by the high phonatory load of teaching and by classroom noise. As passive acoustic requirements of the school buildings are often not respected, the intelligibility inside the classrooms is poor, increasing the teacher's voice loudness. This work is aimed at studying relations between long reverberation times, high noise levels and vocal effort.

Methods Phonatory effort was evaluated in three school complexes, on a sample of nursery (6 subjects), primary (9), junior high (2) and high (8) school teachers. The classrooms were classified as acoustically treated or not. Speech intelligibility was quantified by the speech transmission index (STI). Phonatory doses were correlated to noise exposure levels and to classroom acoustics. The phonatory effort was evaluated with the Ambulatory Phonation Monitor (Kaypentax). 